\title{
Structural Properties of Zn-ZnO Core-Shell Microspheres Grown by Hot-Filament CVD Technique
}

\author{
R. López, ${ }^{1}$ T. Díaz, ${ }^{1}$ G. García, ${ }^{1}$ R. Galeazzi, ${ }^{1}$ E. Rosendo, ${ }^{1}$ A. Coyopol, ${ }^{1}$ \\ M. Pacio, ${ }^{1}$ H. Juárez, ${ }^{1}$ and A. I. Oliva ${ }^{2}$ \\ ${ }^{1}$ Centro de Investigaciones en Dispositivos Semiconductores, Benemérita Universidad Autónoma de Puebla, 14 sur y Avenida, \\ San Claudio, Edif. 137, 72570, PUE, Mexico \\ ${ }^{2}$ Departamento de Física Aplicada, CINVESTAV del IPN, Unidad Mérida, A.P. 73, Cordemex, 97310 Mérida, YUC, \\ Mexico \\ Correspondence should be addressed to R. López, lorr810813@gmail.com
}

Received 25 February 2012; Accepted 22 May 2012

Academic Editor: Grégory Guisbiers

Copyright () 2012 R. López et al. This is an open access article distributed under the Creative Commons Attribution License, which permits unrestricted use, distribution, and reproduction in any medium, provided the original work is properly cited.

\begin{abstract}
We report the hot-filament chemical vapor deposition (HFCVD) growth of $\mathrm{Zn}$ - ZnO core-shell microspheres in the temperature range of $350-650^{\circ} \mathrm{C}$ only using $\mathrm{ZnO}$ pellets as raw material. The samples were characterized by scanning electron microscope (SEM), energy dispersive spectroscopy (EDS), and X-ray diffraction (XRD) techniques. SEM micrographs showed the presence of solid microspheres and a $\mathrm{Zn}-\mathrm{ZnO}$ layer in all samples. The observed heterogeneous morphology on each sample suggested two different growth mechanisms. On the one hand, solid microspheres were formed by means of gas phase nucleation of $\mathrm{Zn}$ atoms. The $\mathrm{Zn}-\mathrm{ZnO}$ layer was formed on the substrate as result of surface reactions. It is possible that $\mathrm{Zn}$ microspheres condensed during the natural cooling of the HFCVD reactor as they were observed on the $\mathrm{Zn}-\mathrm{ZnO}$ layer.
\end{abstract}

\section{Introduction}

Over the last few years, nanotechnology has emerged as an important research field of materials science, since nanostructures exhibit superior physical properties compared to their counterpart bulk materials. Nowadays, nanotechnology has focused on the understanding of the physical properties of nanomaterials and their consequent applications. The controlled fabrication of functional nanostructured materials is an important objective of fundamental and applied research. In addition to nanostructures, sphericallike structures such as hollow microspheres and hemispheres have attracted great interest due to their particular properties such as low density and distinct optical properties. The microspheres are technologically very important among nanostructures because of their large surface-to-volume ratio which is useful in gas sensors and drug delivery $[1,2]$. For many years, $\mathrm{ZnO}$ has been recognized as a promising material. It is a compound that shows unique physical properties for direct application in varistors [3], optical devices [4], gas sensors [5], and so forth. $\mathrm{ZnO}$ has been extensively used as a gas sensing material due to its high electron mobility and good chemical and thermal stability under the sensors operating conditions [6]. Therefore, the synthesis of $\mathrm{ZnO}$ microspheres can be an alternative to gas sensing applications due to the interesting properties that exhibit the $\mathrm{ZnO}$ material and the microsphere structures.

Lately, various techniques have been employed to synthesize nano- and microstructures; however, some of them are complex and considerably expensive. The HFCVD technique is a low cost method with interesting properties. This technique has been a common method in the growth of diamond films due to its simple design and easy scaleup to deposit materials on substrates with large areas. The production of nanoscale materials by the HFCVD technique has focused on the carbon nanotubes synthesis [7-10]. In fact, the HFCVD technique has usually been more efficient in fast synthesis of long carbon nanotubes than other complex CVD techniques such as plasma-enhanced CVD [11-13]. One remarkable characteristic of using the HFCVD technique in the growth 


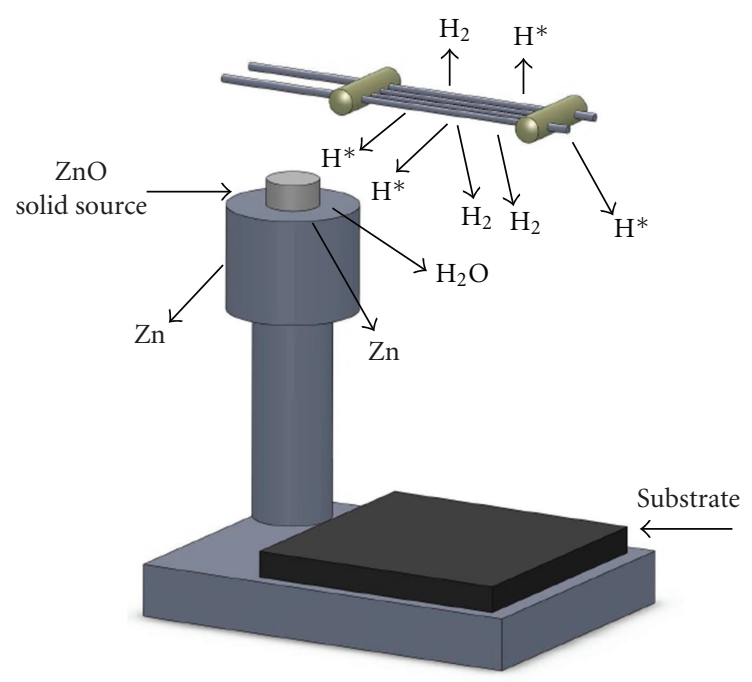

FIGURE 1: Schematic diagram of the experimental configuration of the filament, the $\mathrm{ZnO}$ pellet, and the substrate holder.

of diamond films and carbon nanotubes is that it uses atomic hydrogen as a volatile radical to generate gas-phase active species which, in large numbers, can lead into a possible increase in the growth rate. The above-mentioned advantages suggest this technique as an easy, reproducible, and low-cost alternative for the production of structures at the micro- or nanoscale. In the present work, $\mathrm{Zn}-\mathrm{ZnO}$ microspheres were obtained by the HFCVD technique, but instead of using reactant gases, we used $\mathrm{ZnO}$ pellets as the only source in the formation of gas active species. We also used atomic hydrogen atoms in order to increase the decomposition rate of the $\mathrm{ZnO}$ pellet. We consider that this experimental setup can be a cheaper option to avoid the use of reactant gases that in some cases may be expensive.

\section{Experimental Procedure}

$\mathrm{Zn}-\mathrm{ZnO}$ microstructures were synthesized in a home-made HFCVD system in the temperature range of $350-650^{\circ} \mathrm{C}$. Commercial $\mathrm{ZnO}$ powder (Mallinckrodt) was compressed to obtain $\mathrm{ZnO}$ pellets $(0.3 \mathrm{~g})$, which served as raw material. Molecular $\mathrm{H}$ was used as reactant gas. P-type (100) oriented silicon wafers $\left(\right.$ area $4 \mathrm{~cm}^{2}$ ) and resistivity $\rho=1-3 \Omega-\mathrm{cm}$ were used as substrates. The $\mathrm{ZnO}$ pellets were loaded into the center of the HFCVD reactor (diameter $60 \mathrm{~mm}$, length $350 \mathrm{~mm}$ ) and under of the tungsten filament. The scheme of the configuration of the filament, the $\mathrm{ZnO}$ pellets, and the substrate is shown in Figure 1. Using an AC voltage of $83.4 \mathrm{~V}$, the filament was heated up to $2000^{\circ} \mathrm{C}$ and kept parallel to the substrate holder with a distance of 9,7 , and $5 \mathrm{~mm}$ on each experiment to reach substrate temperatures of 350,500 , and $650^{\circ} \mathrm{C}$, respectively. The process time was 10 seconds in all samples. The $\mathrm{ZnO}$ pellets were placed $2 \mathrm{~mm}$ away from the filament and kept at a temperature of $1500^{\circ} \mathrm{C}$. The filament and the $\mathrm{ZnO}$ pellet temperature zones were monitored by an infrared optical pyrometer. The substrate temperature was measured using a K-type thermocouple. During the microstructures formation, $\mathrm{H}_{2}$ gas is introduced into the reactor, and it is then activated by contact with the hot filament. This generates a quantity of atomic $\mathrm{H}\left(\mathrm{H}^{*}\right)$ [14], which is able to decompose the $\mathrm{ZnO}$ pellet into $\mathrm{Zn}$ gas and water vapor precursors that diffuse towards to the substrate where the reaction takes place.

After the end of the growth process, the HFCVD reactor was naturally cooled down to room temperature. The XRD diffractograms were measured with a Bruker D8 Discover diffractometer using $\mathrm{Cu} \mathrm{K} \alpha$ radiation (1.5418 $\AA$ ). The morphology and elemental analysis of the products were characterized using a scanning electron microscopy (SEM) Phillips XL-30.

\section{Results and Discussion}

\subsection{SEM and EDS Measurements}

3.1.1. Sample Grown at $350^{\circ} \mathrm{C}$. Figure 2 shows the SEM images of the sample grown at $350^{\circ} \mathrm{C}$ by the HFCVD technique. We can see in Figure 2(a) a fibrous-like morphology with localized surface formation of dispersed micrometer clusters. High-magnification image (Figure 2(b)) clearly shows a heterogeneous morphology. Clusters located at the top of the structure show a sphere-like morphology. The surface under spheres presents a porous and nonuniform structure. The formation of spherical particles suggests that the material was liquid (droplet-like) before solidification. However, the growth process for this sample $\left(350^{\circ} \mathrm{C}\right)$ was carried out at lower temperature than the melting point of $\mathrm{Zn}\left(419^{\circ} \mathrm{C}\right)$; therefore, the liquid assisted growth mechanism is ruled out since liquid droplets are not formed onto substrate surface at this temperature [15]. Thus, homogeneous nucleation of $\mathrm{Zn}$ during gas diffusion and its condensation is a strong argument to justify the obtained morphology. Besides, the formation of sphere particles seems to be independent from the substrate because the spheres were observed on the fibrous structure which grows onto the substrate surface, suggesting that they condensed during the natural coolingdown stage. Figure 2(c) shows that the spheres have a mean diameter around 10 micrometers. It can also be seen that they have an irregular surface. High magnification image (Figure 2(d)) shows that the fibrous morphology consists of entangled wire-like structures with irregular surface, and that they are connected with each other. The mean thickness of the wires was about 500 nanometers. Considering the one-dimensional vapor-solid (VS) growth of the wires [16] at $350^{\circ} \mathrm{C}$, their irregular surfaces are ascribed to the formation of clusters that grow by nucleation of some species that do not reach the end of the wire because of their mobility drastically decreases with the natural cooling of the HFCVD reactor.

EDS spectrum of the microspheres (Figure 3(a)) shows only $\mathrm{Zn}$ signals, which may confirms the gas phase nucleation of $\mathrm{Zn}$. In the case of the wires, EDS spectrum (Figure 3(b)) reveals the presence of $\mathrm{Zn}$ and a very little concentration of oxygen. This suggests that wires have $\mathrm{Zn}$ core with a thin $\mathrm{ZnO}$ 


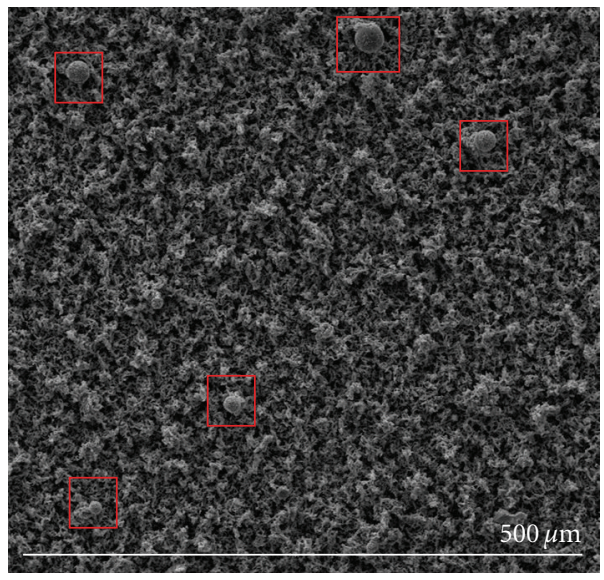

(a)

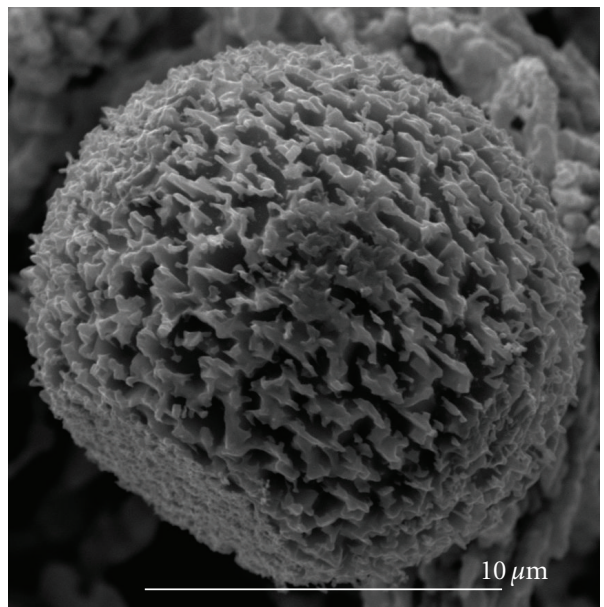

(c)

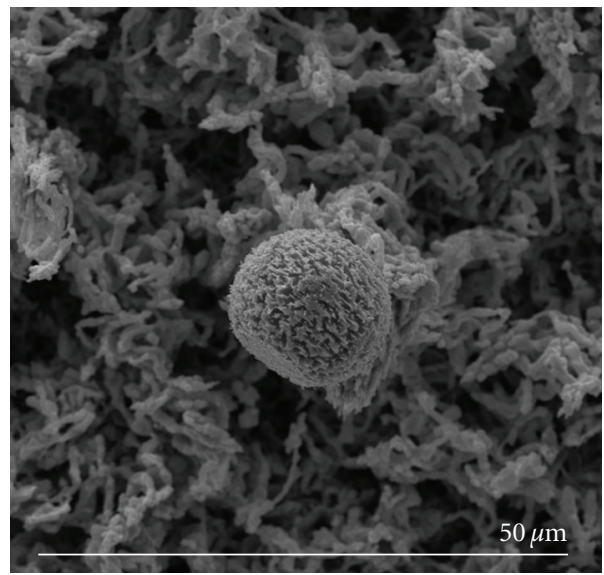

(b)

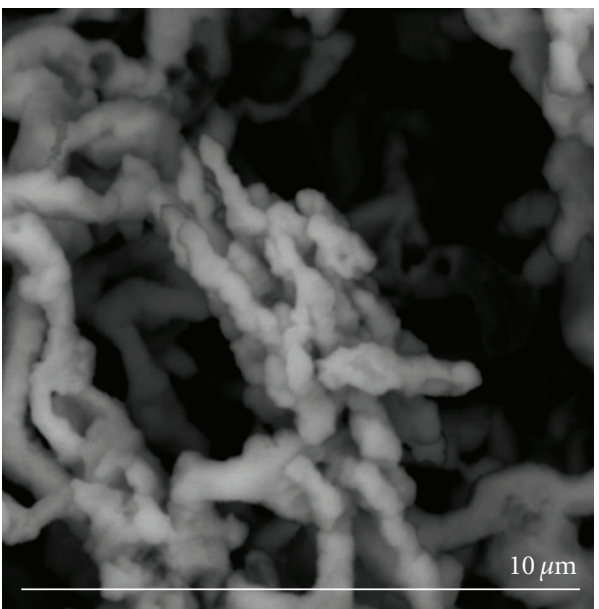

(d)

Figure 2: SEM micrographs of the sample grown at $350^{\circ} \mathrm{C}$; the $\mathrm{Zn}$ microspheres on a $\mathrm{Zn}$-ZnO layer composed by wire-like structures are observed in this figure.

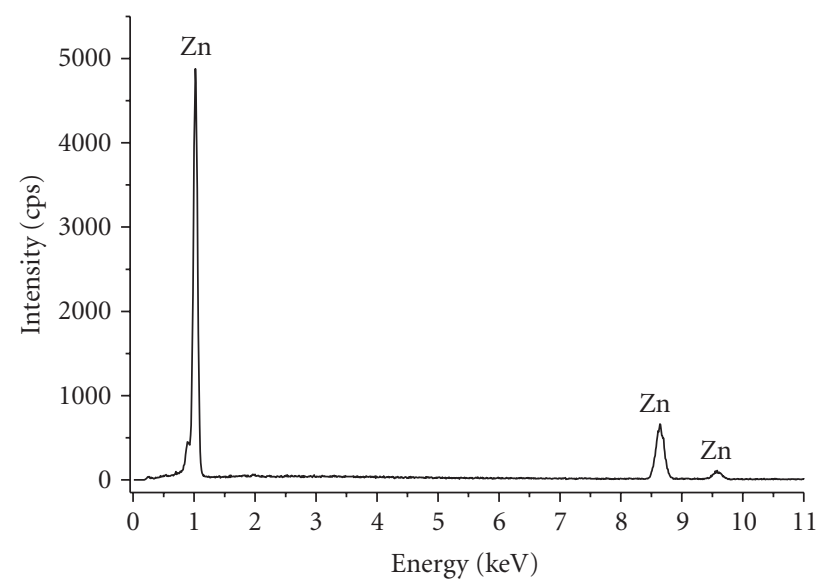

(a)

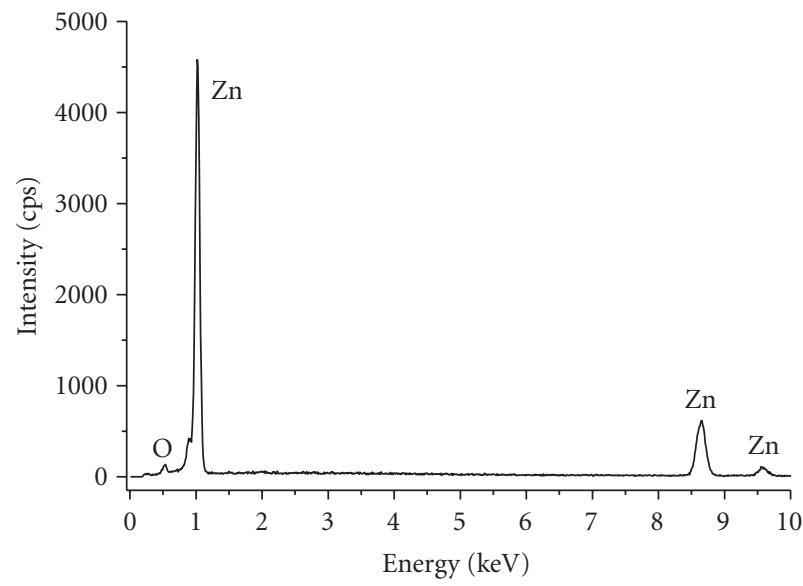

(b)

FIGURE 3: EDS spectra of sample grown at $350^{\circ} \mathrm{C}$ : (a) elemental analysis from a single microsphere and (b) from the wires. 


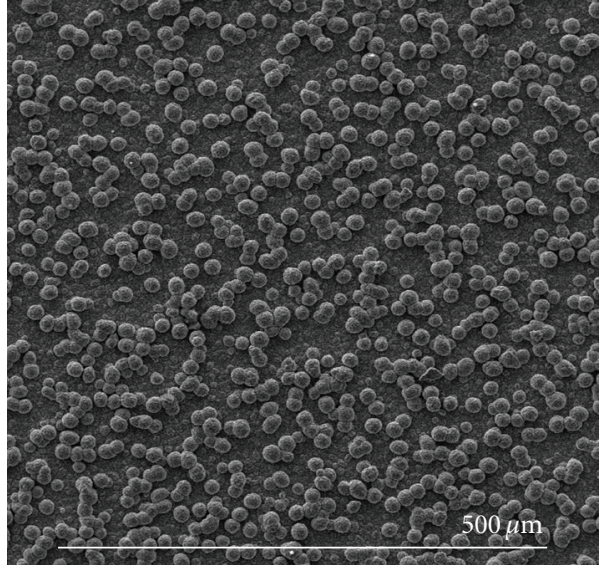

(a)

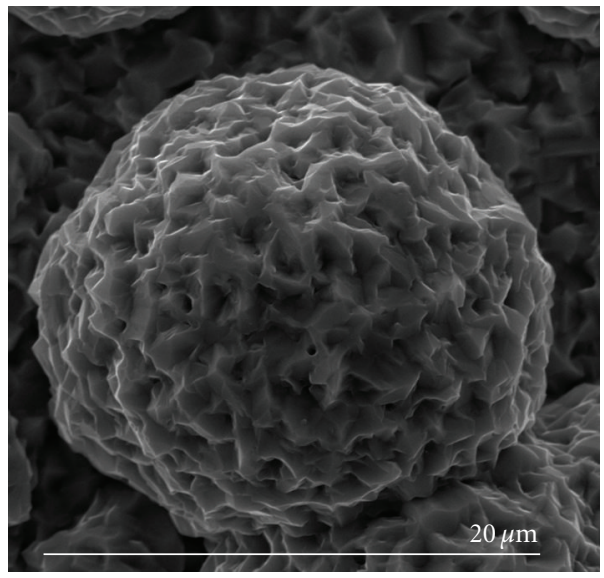

(c)

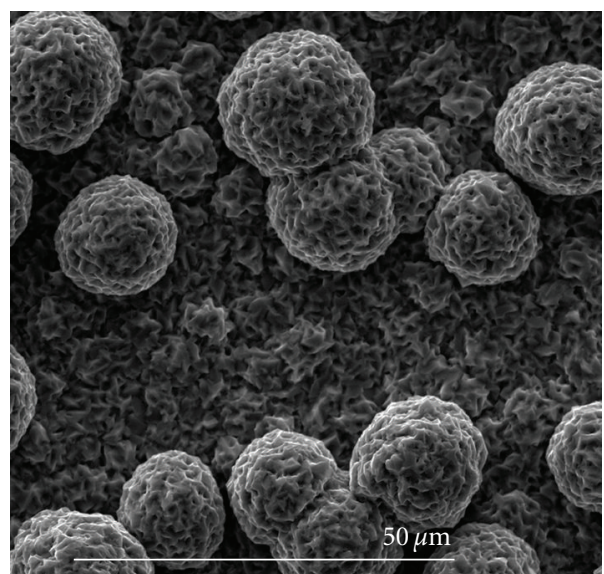

(b)

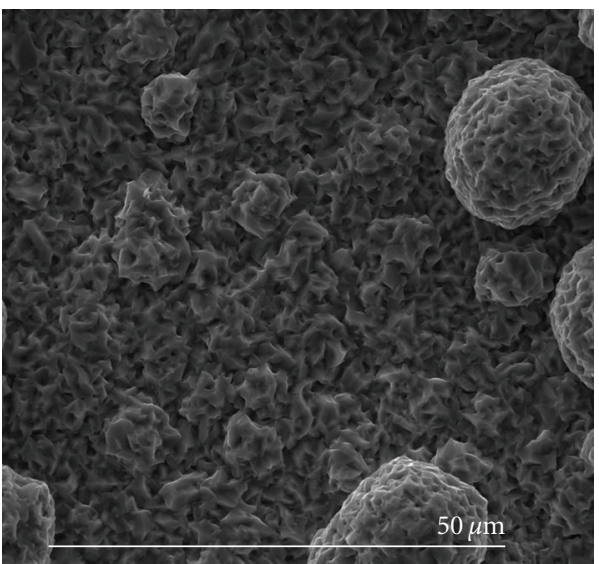

(d)

Figure 4: SEM micrographs of the sample grown at $500^{\circ} \mathrm{C}$; the $\mathrm{Zn}-\mathrm{ZnO}$ microspheres on a compact layer are observed in this figure.

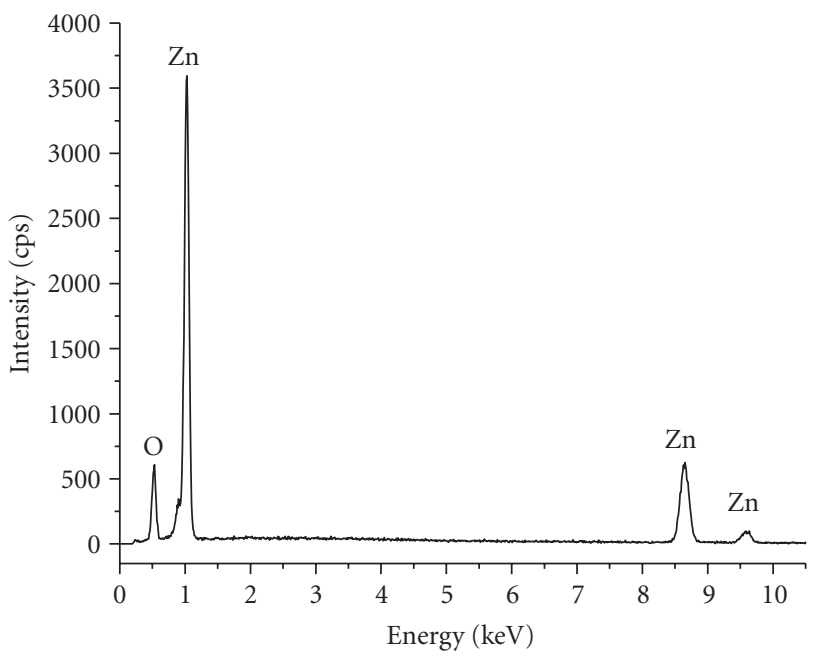

(a)

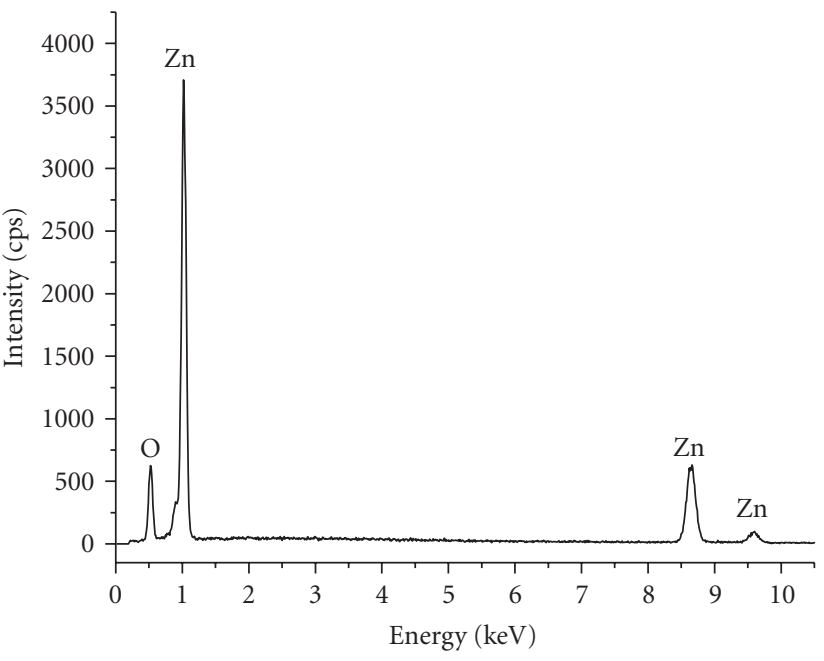

(b)

FIGURE 5: EDS spectra of sample grown at $500^{\circ} \mathrm{C}$ : (a) elemental analysis from a single microsphere and (b) from layer under microspheres. 


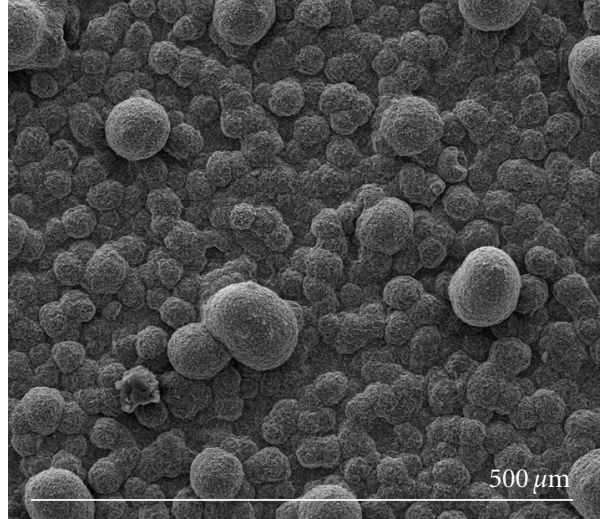

(a)

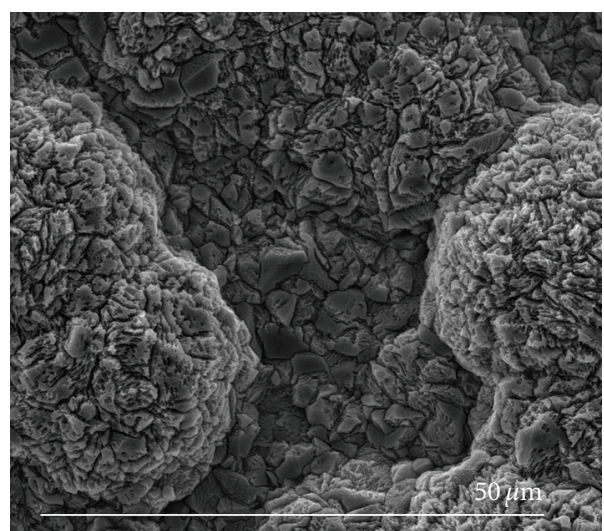

(b)

FiguRE 6: SEM micrographs of sample grown at $650^{\circ} \mathrm{C}$. The large number of microspheres covers the layer grown onto the substrate surface completely.

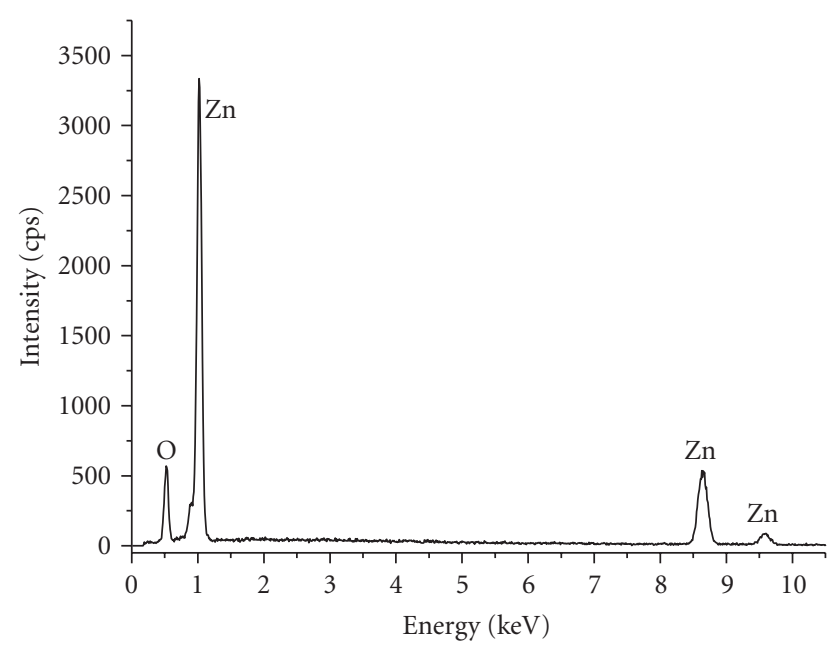

FIGURE 7: EDS spectra of sample grown at $650^{\circ} \mathrm{C}$.

surface layer as was observed by some previous authors [17]. The wires are only partially oxidized due to its surface oxide layer that inhibits the oxidation of the bulk $\mathrm{Zn}$ by forming a protective layer, leading to a very slow oxidation.

3.1.2. Sample Grown at $500^{\circ} \mathrm{C}$. SEM micrographs shown in Figure 4 illustrate the morphology of product grown at $500^{\circ} \mathrm{C}$. Figure $4(\mathrm{a})$ shows the formation of a large number of microspheres distributed on a compact layer. The number of the microspheres is considerably higher than that for sample grown at $350^{\circ} \mathrm{C}$. It is observed that surfaces of both microspheres and the compact layer are very similar and relatively rough (Figure 4(b)). Also, the microspheres have relatively uniform sizes with a mean diameter about 20 micrometers (Figure 4(c)), and some of them are selfassembled leading to spherical packing. The layer under microspheres (Figure 4(d)) exhibits a film-like structure, which is different than the wires formed at $350^{\circ} \mathrm{C}$.

EDS analysis of the microspheres shows $\mathrm{Zn}$ and $\mathrm{O}$ peaks (Figure 5(a)). Although microspheres principally formed in the gas phase and condensed at the slow cooling-down stage at the end of the process, it is possible that some water vapor species oxidizes their surface because the substrate is closer from the hot filament. Therefore, a $\mathrm{Zn}$ microsphere with a $\mathrm{ZnO}$ shell can be obtained by increasing the substrate temperature at $500^{\circ} \mathrm{C}$. EDS measurements of the compact layer formed under the microspheres (Figure 5(b)) show Zn and $\mathrm{O}$ peaks, indicating again that substrate surface reaction includes $\mathrm{Zn}$ layer formation and a postsurface oxidation process. Additionally, this result suggests that this compact layer is sufficiently thick to prevent the silicon substrate contribution.

3.1.3. Sample Grown at $650^{\circ} \mathrm{C}$. Figure 6 shows SEM micrographs of the sample grown at $650^{\circ} \mathrm{C}$. The obtained product exhibits a dense structure composed by solid microspheres (Figure 6(a)). The microspheres have uniform sizes of approximately $50 \mu \mathrm{m}$. This image shows no further layer under microspheres as seen for samples grown at 350 and $500^{\circ} \mathrm{C}$. It could be suggested that the large number of condensed microspheres and its coalescence lead the microspheres to cover the layer grown onto the substrate completely. High magnification SEM image of the microspheres is shown in Figure 6(b). It is observed that the shape of some microspheres is lost by coalescence with the tendency to integrate to the under layer. EDS spectrum (Figure 7) of this sample shows $\mathrm{Zn}$ peaks with a low contribution of oxygen, which confirms the presence of a $\mathrm{Zn}-\mathrm{ZnO}$ structure.

3.2. XRD Measurements. Figure 8 shows the XRD spectra of the microspheres grown at 350,500 , and $650^{\circ} \mathrm{C}$ by the HFCVD technique. The observed diffraction peaks in all recorded XRD patterns are in agreement with the 


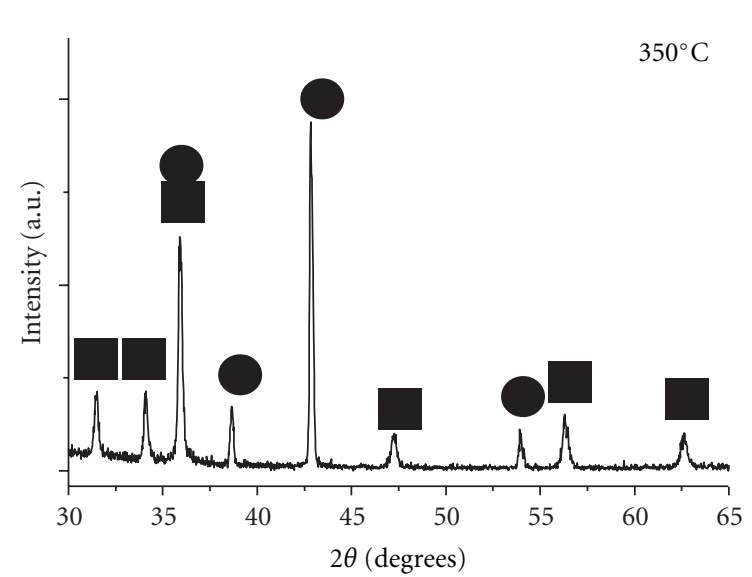

(a)

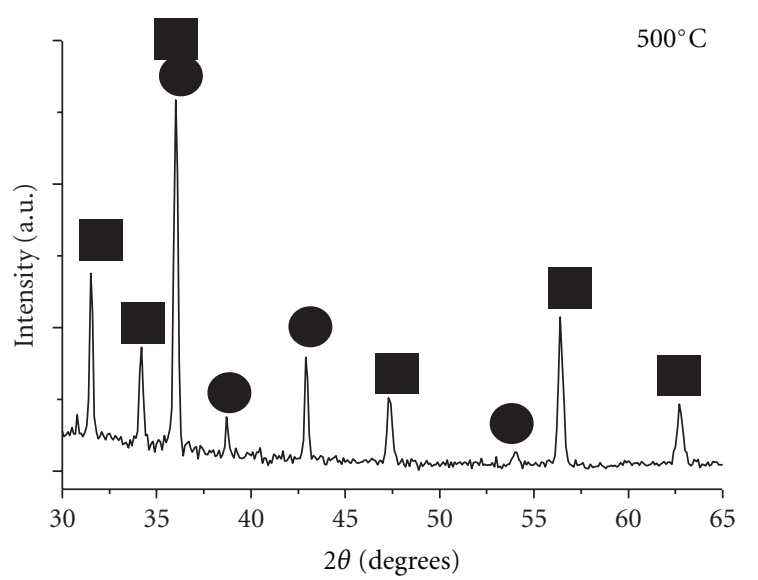

(b)

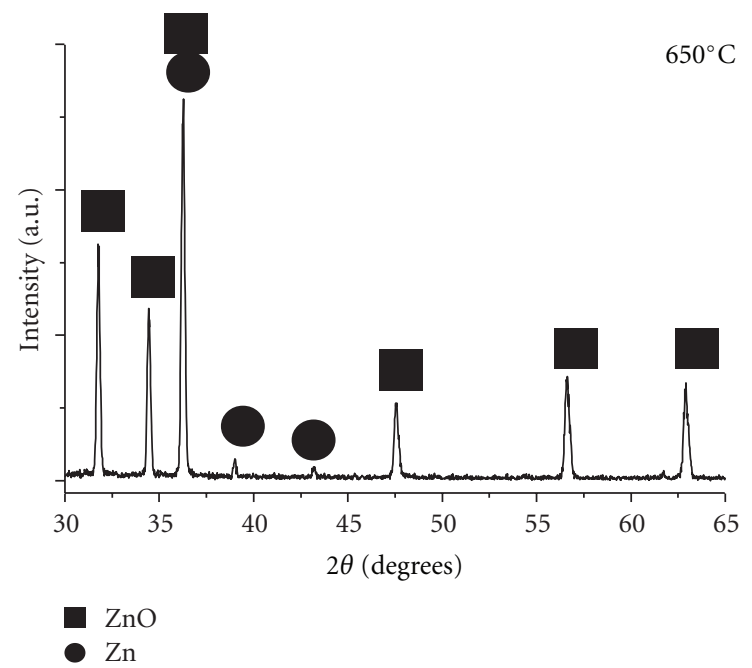

(c)

FIGURE 8: XRD spectra of samples grown at 350,500 , and $650^{\circ} \mathrm{C}$ by the HFCVD technique.

JCPDS 00-035-1451 and 00-004-0831 cards corresponding to $\mathrm{ZnO}$ and $\mathrm{Zn}$ hexagonal crystal structures, respectively. No peaks of any other phase were detected; this rules out the possibility of sample contamination by the tungsten filament. The presence of $\mathrm{ZnO}$ and $\mathrm{Zn}$ phases in all XRD spectra corroborates the fact that both microspheres and the layer that grow on the substrate are only superficially oxidized independently from the substrate temperature. It is observed that peak at $43.10^{\circ}$ corresponding to $\mathrm{Zn}$ (101) plane in the XRD diffractogram of sample grown at $350^{\circ} \mathrm{C}$ is the strongest. We suggest that the main contribution of $\mathrm{Zn}$ crystals on this sample comes from the bulk $\mathrm{Zn}$ of the wires due to the low number of $\mathrm{Zn}$ microspheres placed at the top of the structure. At higher substrate temperatures, the intensity ratio of the $\mathrm{Zn}$ peaks to the $\mathrm{ZnO}$ peaks decreases, suggesting a better oxidation characteristic. It is known that in $\mathrm{Zn}-\mathrm{ZnO}$ structures, the bulk oxidation is controlled by the outdiffusion of $\mathrm{Zn}$ through the surface $\mathrm{ZnO}$ layer [18, 19]. Thus, the increase of the substrate temperature enhances the mobility of $\mathrm{Zn}$, leading to the outdiffusion of these atoms across of the thin $\mathrm{ZnO}$ layer from the microspheres and from the layer under microspheres. This results in bigger $\mathrm{Zn}-\mathrm{ZnO}$ microspheres as a result of this physical mechanism.

\section{Conclusion}

$\mathrm{Zn}$ microspheres and $\mathrm{Zn}-\mathrm{ZnO}$ core-shell microspheres were obtained in the temperature range of $350-650^{\circ} \mathrm{C}$ by HFCVD technique. The $\mathrm{Zn}$ microspheres were observed on a $\mathrm{Zn}$ $\mathrm{ZnO}$ surface layer, which is formed on the silicon substrate surface during the experimental process. XRD and EDS results suggested that all grown $\mathrm{Zn}$ microspheres are only partially oxidized independently of the substrate temperature. We suggest that the $\mathrm{Zn}-\mathrm{ZnO}$ microspheres condensed during the natural cooling of the HFCVD reactor, and they are not formed as a result of the vaporliquid-solid growth mechanism. The formation of $\mathrm{Zn}-\mathrm{ZnO}$ microspheres by the HFCVD technique could be an easy 
and low cost way to produce these structures at the large scale.

\section{Acknowledgments}

This work was financially supported by CONACYT, VIEPBUAP, and ICUAP-BUAP. The authors also acknowledge S\&C Associates for proofreading of the paper.

\section{References}

[1] K. M. Sulieman, X. Huang, J. Liu, and M. Tang, "Controllable synthesis and characterization of hollow-opened $\mathrm{ZnO} / \mathrm{Zn}$ and solid Zn/ZnO single crystal microspheres," Nanotechnology, vol. 17, no. 19, pp. 4950-4955, 2006.

[2] W. Ding, F. Chun, X. Qiang, and P. Yi, "Gas sensing properties of hollow $\mathrm{SnO}_{2}$ microspheres prepared by a template process," Sensor Letters, vol. 9, pp. 184-187, 2011.

[3] M. H. Aslan, A. Y. Oral, E. Menşur, A. Gül, and E. Başaran, "Preparation of C-axis-oriented zinc-oxide thin films and the study of their microstructure and optical properties," Solar Energy Materials and Solar Cells, vol. 82, no. 4, pp. 543-552, 2004.

[4] A. E. Jimenez and J. A. Soto, "Optical transmittance and photoconductivity studies on $\mathrm{ZnO}: \mathrm{Al}$ thin films prepared by the sol-gel technique," Solar Energy Materials and Solar Cells, vol. 52, no. 3-4, pp. 345-353, 1998.

[5] M. Suchea, S. Christoulakis, K. Moschovis, N. Katsarakis, and G. Kiriakidis, "ZnO transparent thin films for gas sensor applications," Thin Solid Films, vol. 515, no. 2, pp. 551-554, 2006.

[6] Q. Wan, Q. H. Li, Y. J. Chen et al., "Fabrication and ethanol sensing characteristics of $\mathrm{ZnO}$ nanowire gas sensors," Applied Physics Letters, vol. 84, pp. 3654-3656, 2004.

[7] B. Gan, J. Ahn, Q. Zhang et al., "Branching carbon nanotubes deposited in HFCVD system," Diamond and Related Materials, vol. 9, no. 3, pp. 897-900, 2000.

[8] K. H. Kim, E. Lefeuvre, M. Châtelet, D. Pribat, and C. S. Cojocaru, "Laterally organized carbon nanotube arrays based on hot-filament chemical vapor deposition," Thin Solid Films, vol. 519, no. 14, pp. 4598-4602, 2011.

[9] S. L. Katar, D. Hernandez, A. B. Labiosa et al., "SiN/bamboo like carbon nanotube composite electrodes for lithium ion rechargeable batteries," Electrochimica Acta, vol. 55, no. 7, pp. 2269-2274, 2010.

[10] W. W. Yi and Q. Q. Yang, "Aligned growth and alignment mechanism of carbon nanotubes by hot filament chemical vapor deposition," Applied Physics A, vol. 98, no. 3, pp. 659$669,2010$.

[11] J. H. Yim, S. Choi, S. Lee, and K. H. Koh, "Synthesis of very dense carbon nanotube bundles using silica supported metal catalyst," Journal of Vacuum Science and Technology B, vol. 22, pp. 1308-1311, 2004.

[12] K. H. Park, J. H. Yim, S. Lee, and K. H. Koh, "Catalyst-assisted hot filament chemical vapor deposition and characterization of carbon nanostructures," Thin Solid Films, vol. 501, no. 1-2, pp. 233-237, 2006.

[13] H. Umemoto, K. Ohara, D. Morita, Y. Nozaki, A. Masuda, and H. Matsumura, "Direct detection of $\mathrm{H}$ atoms in the catalytic chemical vapor deposition of the $\mathrm{SiH}_{4} / \mathrm{H}_{2}$ system," Journal of Applied Physics, vol. 91, no. 3, pp. 1650-1656, 2002.

[14] S. J. Harris and A. M. Weiner, "Reaction kinetics on diamond: measurement of $\mathrm{H}$ atom destruction rates," Journal of Applied Physics, vol. 74, pp. 1022-1026, 1993.

[15] T. W. Kim, T. Kawazoe, S. Yamazaki, M. Ohtsu, and T. Sekiguchi, "Low-temperature orientation-selective growth and ultraviolet emission of single-crystal $\mathrm{ZnO}$ nanowires," Applied Physics Letters, vol. 84, no. 17, pp. 3358-3360, 2004.

[16] S. Kar, T. Ghoshal, and S. Chaudhuri, "Simple thermal evaporation route to synthesize $\mathrm{Zn}$ and Cd metal nanowires," Chemical Physics Letters, vol. 419, no. 1-3, pp. 174-178, 2006.

[17] J. G. Wang, M. L. Tian, N. Kumar, and T. E. Mallouk, "Controllable template synthesis of superconducting $\mathrm{Zn}$ nanowires with different microstructures by electrochemical deposition," Nano Letters, vol. 5, no. 7, pp. 1247-1253, 2005.

[18] J. O. Cope, "Kinetics of the oxidation of molten zinc," Transactions of the Faraday Society, vol. 57, pp. 493-503, 1961.

[19] A. C. S. Sabioni, "About the oxygen diffusion mechanism in ZnO," Solid State Ionics, vol. 170, no. 1-2, pp. 145-148, 2004. 

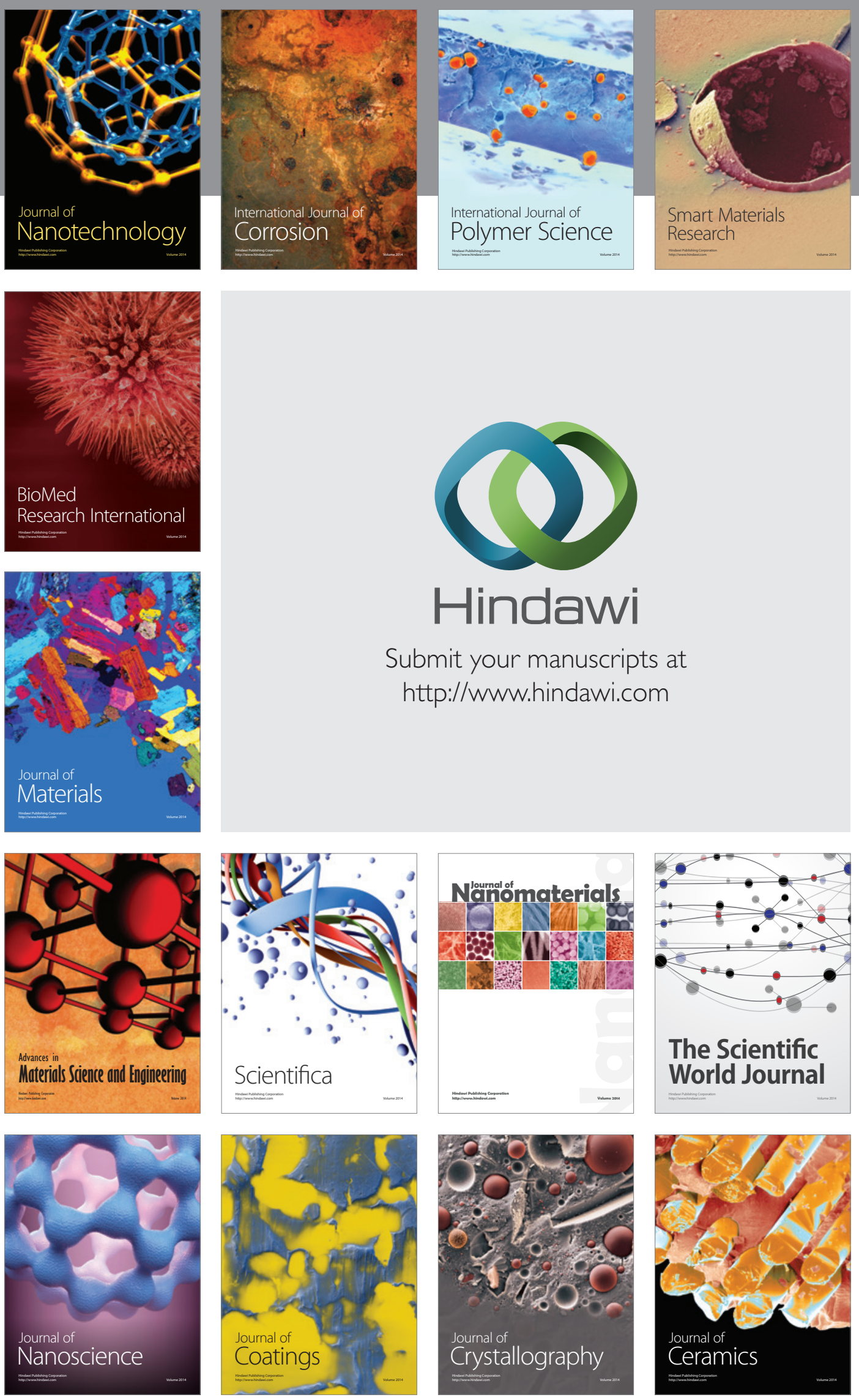

The Scientific World Journal

Submit your manuscripts at

http://www.hindawi.com

\section{World Journal}

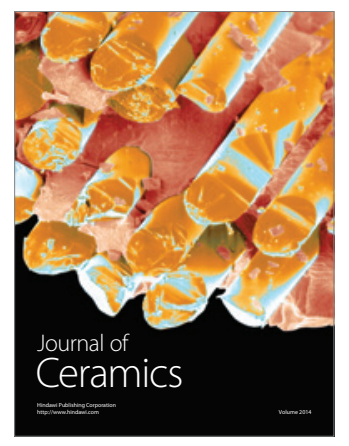

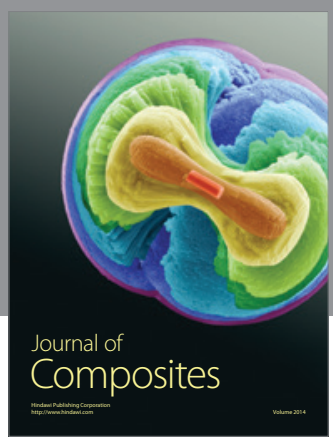
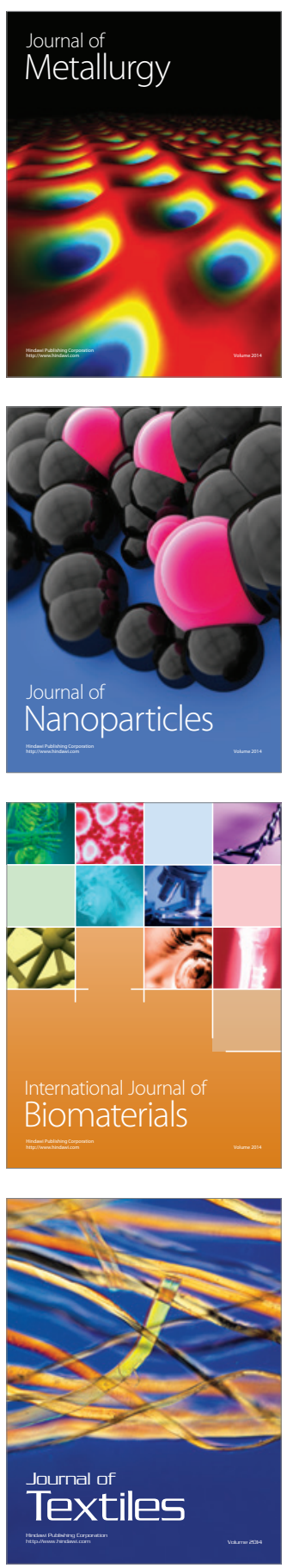